\title{
Matching Probation Officer and Delinquent
}

\author{
Gilbert Geis \\ Assistant Professor, Department of Sociology, University of Oklahoma \\ Fred W. Woodson \\ Director, Tulsa County Juvenile Court, Tulsa, Oklahoma
}

$\mathrm{C}$ ASEWORK procedure in the handling of delinquents on probation generally operates on two assumptions: first, that the youth will be given the benefit of community services made available to him through the activities of the probation officer; and second, that the relationship between the youngster and the probation officer, the interacting of their personalities, will have a positive effect leading to a healthier social adjustment for the youth.

There is considerable evidence that benefit can result from a constructive adult-youth relationship formed for the deliberate purpose of providing the youth with an atmosphere in which he is encouraged to re-orient what has previously been antisocial behavior. On a semiprofessional level such organizations as the Big Brothers operate almost exclusively on this premise.

Maximum success in the first aspect of probation casework procedure-the exploitation of available community resources-occurs when a probation staff is adequately trained and especially cognizant of the various routes along which a delinquent boy may be directed for help. Vigilance must be exercised to see that the probation staff keeps abreast of the developments in community aid programs and stays aware of the various treatment nuances in available facilities; that is, of their likely advantages and disadvantages for given individuals, as well as their special services. Many valuable suggestions along this line pervade the literature on probation.

Less attention, however, has been focused on the second problem, that of deriving the best results possible from the officer-delinquent match. Essentially, the problem springs from the difficulties involved in taking organized account of the seemingly infinite variations of personality types, both of officers and probationers, and then of determining the presumptive outcome of the matching of two of these types, with the added complication of the dynamics of the relationship as it progresses.

Little research appears to have been directed toward resolving the problem of probation matching. One of the most extensive investigations of delinquency control, the well-known Cambridge-Somerville study, ${ }^{1}$ made some faltering, intuitive steps along the lines of adequate matching, but never really grappled in an empirical way with the basic problem. Called in

1 Edwin Powers and Helen Witmer, $A n$ Experiment in the Prevention of Delinquency: The Cambridge-Somerville Youth Study, New York, Columbia University Press, 1951. 
later to analyze the Cambridge-Somerville results, Helen Witmer attempted to remold the study's original experimental design to produce some answers to the matching dilemma, but these answers were, largely because of the nature of the material, rather unsatisfactory.

In the Cambridge-Somerville study, only a few general matching rules were observed. Women counselors, for example, were usually assigned to younger boys, and men sometimes replaced women if the youths appeared to be particularly difficult. Typical probation work operates on about the same principles. In fact, some statutes require that very young boys be dealt with only by women probation officers. In addition, female probationers are almost invariably assigned to women officers. Such broad rules, of course, fail to take into account the particular needs of clients beyond those which they would seem to share with a stereotyped sex-age group. More important, they fail to utilize to the utmost the special abilities of the probation officers themselves.

Further refinement of the matching process in larger urban areas where such a process would be practicable is obviously desirable. The remainder of this paper will not pretend to resolve the problem or to present a complete set of working rules. Rather its purpose is, first, to draw attention to the importance of a matching approach in probation work; and second, to explore some of the avenues leading to a solution of problems involved in matching.

\section{Probation Officers}

Professional probation practice is based on recognized casework principles which may be learned from systematic instruction. Leading probation workers stress, however, that academic training must be combined with a personal approach that often seems to border on art. Appointment to probation positions, on the other hand, is essentially based on the applicant's training and knowledge rather than on his personality assets.

The basic assumption must be made that all the members of a probation staff are technically competent and possess, in addition, special, though different, casework attributes. The initial problem then becomes one of determining more precisely the nature of these attributes. We suggest that each member of the staff be classified in a number of seemingly relevant areas, such as (1) identification traitssex, $\operatorname{age}^{2} ;(2)$ background, experience, and interests; (3) personality traits as determined by a battery of psychological examinations; and (4) expressed interest in various types of clients. ${ }^{3}$ Categorized lists of probationers might be drawn up and the worker would choose from these lists the ones that he believes he would like to work with and could help the most.

\section{Probationers}

Most probation staffs possess, or will possess, considerable material on the attributes of the clients being handled by them. The problem becomes one of classifying this material in a meaningful way so that handy, workable portraits of delinquent types may be obtained. Probationers can be classified according to the first three

${ }^{2}$ Some youths do very well when the officer represents, by virtue of his age, an acceptable authority figure. Other probationers have considerable difficulty adjusting to persons far beyond themselves in years.

${ }^{3}$ A more elaborate list of important items can be found in John O. Reinemann, "Principles and Practices of Probation," Federal Probation, December, 1950, p. 27. 
categories outlined for officers. Very important also would be the delinquency pattern that the individual is following, though this item might well be subordinated to the type of person the prospective client is.

Family relationship must also be given a great amount of weight in ascertaining the characteristics of the individual to be handled. If we accept the summary finding of the Gluecks, based on careful research, that the family and parents play a "crucial role... in the inculcation of socially acceptable, or antisocial, ideals and habits," 4 then the shortcomings of family living in each particular case must be carefully charted. We must seek to discover in what way the individual's family appears to be inadequate in satisfying his needs. We must find out whether any members of the family are missing and what the particular deficiencies are of those present. Then, in light of all this information, the critical question may be answered: Which of the probation officers appears to be most likely to stop the delinquency pattern in this youngster's career?

The operation of this process at a beginning level can be illustrated by some recent cases handled at the Tulsa Juvenile Court:

One boy appearing before the court told about his interest in radio. A court caseworker had a similar interest and on this basis, since no other factors appeared which would make the match undesirable, the case was assigned to this worker. Radio became the catalyst which enabled the worker to interact constructively with the boy. A

4 Sheldon and Eleanor Glueck, testimony before the Subcommittee to Investigate Juvenile Delinquency, Committee of the Judiciary, United States Senate, November 20, 1953, p. 98 . close relationship was quickly formed; it served as a basis for attacking numerous personality problems besetting the youngster.

Another member of the Tulsa staff, it was found, is particularly well equipped to work with hostile, defiant boys. He is relaxed, patient, and easygoing, and he never "pushes" a case.

On the other hand, bad matches can be made if care is not exercised to check carefully the relevant characteristics of both client and caseworker. In one such instance in another city, a young boy was assigned to a male staff worker who, on the surface, appeared quite capable of handling the situation. Early in the case, however, the detention home report referred to the boy's habit of going about the home licking the feet of other boys while they were in bed. When the caseworker learned this, both the act itself and its sexual implications upset him so badly that he became ill. Actually, he would have been a stronger person had he been able to work through his own problem in relation to this case, but on a short-term basis this was not feasible.

\section{The Factor of Timing}

One of the major situations undercutting probation matching schemes in various areas relates to the chronology of handling cases. Probation staffs may be told that a certain boy has been apprehended and that the court desires a prehearing investigation. Not until this investigation is well launched will certain important information-facts that may be essential to assigning the boy correctlybe at hand. Meanwhile, which staff member should conduct the prehearing check? And, secondly, will it not represent a loss in efficiency and rapport to reassign the case later? 
Solution of this dilemma lies in determining as early as possible the major points of information necessary for matching. As Sutherland and Cressey point out, "ideally, experts would always make the diagnosis before the offender is admitted to probation." If this is done, at least a psychologically suitable portrait of the individual will be available before assignment. Information on the boy and his family, as well as on other aspects of his social environment, will have to be elicited from the boy himself, and on the basis of this collected data a logical probation assignment might be made.

The elements to be considered in the match, therefore, must be the kind that can be obtained early and rather easily. Continual follow-ups should be made to determine the precise importance of the information being used to make the assignment and to weigh the validity of other items which might be substituted or added to enhance the worth of the matching program.

The administrative problem of balancing the caseloads so that the most suitable officer is available when his counterpart in casework comes within the staff's jurisdiction can be troublesome. Assignments should be made with the aim of helping those probationers who can benefit from the probation experience, which means avoiding the waste of spending disproportionate amounts of time and talent in noble tries on cases which have a very low predictable outcome of success.

Another difficulty that should be mentioned concerns the length of service that the court anticipates rendering. If the probation period is to

- Edwin H. Sutherland, Principles of Criminology, revised by Donald R. Cressey, fifth edition, Philadelphia, J. B. Lippincott Company, 1955, p. 431. be of short duration, the case should be assigned to a worker with whom the probationer will relate quickly and easily. A boy who has a warm, accepting mother and a domineering, firm father will probably develop a fast and positive relationship with a mother-like woman worker. Should there be indications that the case will be of longer duration, however, it would seem advisable, other things being equal, for the same boy to be assigned to a male worker. While rapport will be more difficult to establish, the whole casework process will be more meaningful to the boy if he can be helped to see through the problem that has arisen from the unwholesome "male world" his father represents.

\section{The Process of Evaluation}

The value of any matching program and, in fact, of any therapeutic regime, should be established by a systematic evaluation of results. This allows for a constant streamlining of procedure and theory and for an avoidance of error duplication.

Evaluation of matching should proceed along two lines. One approach should be based on an analysis of results obtained in cases completed during a prior period; the other should be based on a study of cases being handled under the matching system.

Past cases should be examined in terms of categories which will be useful in classifying current cases. The analysis should determine which officers had the greatest success with certain types of cases. Then such cases can be funneled to them in the future.

As a last word, it cannot be underlined too strongly that the matching program should never represent an invidious method of competition among staff members. It is pointless to deny that some officers will succeed 
better than others with practically any type of case. This differential ability will be found in any type of operation. In probation, each officer has something of his own, something particular, to contribute. The aim of the matching program is to make the most intelligent use of each member's abilities. Staff esprit de corps, the abiding interest of each of the staff members in the total success of the office as a unit, is a vital element in achieving maximum results from a matching program.

This article is an attempt to draw attention to the importance of assigning the most suitable officers to cases, a procedure that goes to the roots of probation work. It is not the last word on the subject, and we hope it will stimulate others to contribute their thinking, to criticize and evaluate what we have said here, and perhaps to describe work along the same lines in their departments.

[Readers are urged to send to the NPPA JourNar their comments on the classification problems discussed above by Professor Geis and Mr. Woodson. Full-length manuscripts that will explore in detail the issues involved in the proposed matching plan will be particularly welcome.-EDITOR]

The criminal law represents the pathology of civilization. But just as the study of animal pathology has illumined normal physiology, and has been helpful in physical hygiene, or just as the study of insanity has thrown light on mental processes and has been at times somewhat helpful in mental hygiene, so the study of criminality may illumine normal human motives and be helpful in bringing about just and humane social relations. The necessary condition for this study, however, is the most rigorous intellectual integrity, the concentration on seeing the facts as they are, regardless of natural sentimental predilections. We must learn to live in an imperfect world, though we dare not relax the effort to make it better. 